\title{
Infiltration with Agrobacterium tumefaciens Induces Host Defense and Development-Dependent Responses in the Infiltrated Zone
}

\author{
Gail J. Pruss, ${ }^{1}$ Eugene W. Nester, ${ }^{2}$ and Vicki Vance ${ }^{1}$ \\ ${ }^{1}$ Department of Biological Sciences, University of South Carolina, Columbia, SC 29208 U.S.A.; ${ }^{2}$ Department \\ of Microbiology, University of Washington, Seattle, WA 98195, U.S.A.
}

Submitted 20 December 2007. Accepted 19 August 2008.

\begin{abstract}
Despite the widespread use of Agrobacterium tumefaciens to transfer genes into plant systems, host responses to this plant pathogen are not well understood. The present study shows that disarmed strains of Agrobacterium induce distinct host responses when infiltrated into leaves of Nicotiana tabacum. The responses are limited to the infiltrated zone and consist of i) induction of pathogenesis-related $(P R)$ gene $P R-1$ expression and resistance to subsequent infection with tobacco mosaic virus, ii) chlorosis and loss of chloroplast rRNAs, and iii) inhibition of leaf expansion. Induction of the latter two sets of responses depends on the age of the leaf and is most apparent in young leaves. Strains with or without binary vectors induce all the responses, showing that DNA transfer is neither required nor inhibitory. A.tumefaciens cured of the tumor-inducing (Ti) plasmid is slightly defective for induction of the three responses, showing that $\mathrm{Ti}$ plasmid-encoded factors produced by the disarmed strains contribute only slightly. However, T-DNA-encoded factors alter at least one of the host responses, because infiltration with the oncogenic strain C58 induced more pronounced chlorosis than the disarmed control. Auxin is one of the T-DNA products responsible for disease induction by oncogenic $A$. tumefaciens We found that C58-infiltrated zones-but not those infiltrated with the disarmed control-have increased levels of miR393, a microRNA that represses auxin signaling and contributes to antibacterial resistance.
\end{abstract}

Additional keywords: plant defense, transient expression

Agrobacterium spp. are unique plant pathogens that cause disease by transferring and integrating DNA (T-DNA) of the bacterium into the plant genome (Escobar and Dandekar 2003; Gelvin 2003; McCullen and Binns 2006). This ability to transfer DNA into plants has made Agrobacterium tumefaciens the workhorse of modern plant molecular biology for transient expression studies as well as for constructing transgenic plants. The T-DNA is part of the tumor-inducing (Ti) plasmid of the bacterium and carries genes for the biosynthesis of the plant hormones auxin and cytokinin and of compounds (opines) metabolized by the bacterium. Expression in the plant of the biosynthetic genes introduced by the T-DNA leads to increased proliferation of the transformed and neighboring plant cells, resulting in a tumor-like growth termed crown gall. Agrobacte-

Corresponding author: G. J. Pruss; Telephone: +1.803.777.7030; Fax: +1.803.777.4002; E-mail: pruss@biol.sc.edu rium strains used for genetic engineering have been disarmed of their tumor-inducing properties by deleting the T-DNA, and genes to be transferred into the plant are cloned into a separate vector (Gelvin 2003; Hellens et al. 2000).

A. tumefaciens has long been considered to be a pathogen that does not significantly activate host defenses: It does not have the classical hrp gene cluster characteristic of most other species of phytopathogenic bacteria (Goodner et al. 2001; Wood et al. 2001) and it fails to elicit a hypersensitive response (Herlache et al. 2001), although it transfers proteins into plant cells. Moreover, A. tumefaciens inhibits the hypersensitive response elicited by an unrelated bacterial strain (Robinette and Matthysse 1990); A. vitis, in contrast, elicits a hypersensitive response. Such observations, however, provide only a very limited view of host defense. Plant defense against pathogens is highly complex and multifaceted (Chisholm et al. 2006; Eulgem 2005; Jones and Dangl 2006). It includes not only the salicylic acid (SA), jasmonic acid (JA), and ethylene-signaling pathways (Hammond-Kosack and Parker 2003; Kunkel and Brooks 2002), but also the short-interfering RNA (siRNA) and microRNA (miRNA) pathways, which play important roles in many cellular processes, including stress and defense responses (Bonnet et al. 2006; Dunoyer et al. 2006; Katiyar-Agarwal et al. 2006; Mallory and Vaucheret 2006; Navarro et al. 2006). Furthermore, in addition to recognizing specific virulence factors, plants also respond to conserved molecular patterns that are characteristic of microbial organisms but not plants (Nurnberger et al. 2004). Flagellin, cold-shock protein, and elongation factor Tu (EF-Tu) are three such general elicitors of plant defense (Felix and Boller 2003; Felix et al. 1999; Kunze et al. 2004; Zipfel et al. 2004). Adding to the complexity, different plant species respond to different general elicitors. Cold-shock protein is a general elicitor only in solanaceous plants whereas EF-Tu has elicitor activity only in cruciferous plants (Felix and Boller 2003; Kunze et al. 2004). Both cold-shock protein and EF-Tu from A. tumefaciens are general elicitors of host defense, as demonstrated by their alkalinization-inducing activity in plant cell cultures (Felix and Boller 2003; Kunze et al. 2004), and treating plants with a soluble extract of A. tumefaciens protects against an unrelated pathogen (Zipfel et al. 2004).

Yet another layer of complexity in the interplay between plant and pathogen is that pathogens have evolved to block defense responses triggered by general elicitors (He et al. 2007). The complexity of the A. tumefaciens-host interaction is reflected in the results of studies characterizing changes in host gene expression induced by that pathogen. Groups using different plant cell culture systems reached contradictory conclu- 
sions regarding the extent to which $A$. tumefaciens induced host defenses (Ditt et al. 2001, 2006; Veena et al. 2003). Whereas a group using Ageratum and Arabidopsis cell cultures concluded that A. tumefaciens induces defense (Ditt et al. 2001, 2006), one using tobacco cell cultures concluded that $A$. tumefaciens represses plant defense responses after transiently inducing them (Veena et al. 2003). A further study involving root transformation of Arabidopsis concluded that A. tumefaciens interferes with SA-dependent defense and inhibits induction of pathogenesis-related $(P R)$ genes (Gaspar et al. 2004). Studies focusing on specific pathways have provided functional evidence that $A$. tumefaciens activates, utilizes, and suppresses plant defenses. Mitogen-activated protein (MAP) kinase defense signaling in Arabidopsis has been implicated in both restricting and promoting transient transformation by disarmed strains of Agrobacterium (Djamei et al. 2007; Zipfel et al. 2006), and RNA silencing against T-DNA genes is first triggered and then suppressed by an oncogenic strain (Dunoyer et al. 2006).

Despite this evidence for multiple interactions of $A$. tumefaciens with host defenses, we do not yet have a very clear or complete understanding of host responses to this pathogen. In addition, a question that is largely ignored is what implication these competing interactions have for Agrobacterium-mediated transient expression studies, which are often used to study plant defense and stress responses. The present study arose when effects attributable to A. tumefaciens interfered with our transient expression experiments. We show that infiltrating $A$. tumefaciens into tobacco leaves activates long-lived responses within the infiltrated zone. Some of these are associated with host defense and others depend on the age of the leaf. Many of the responses appear to be part of a general response of the plants to bacteria because similar effects are produced by infiltration with Escherichia coli.

\section{RESULTS}

Agroinfiltration induces $P \boldsymbol{R}-1$ and resistance to Tobacco mosaic virus in the infiltrated zone.

In the course of transient expression studies that involved infiltrating tobacco leaves with disarmed strains of A. tumefaciens, we found that the infiltrated regions became highly resistant to subsequent infection by Tobacco mosaic virus (TMV). Even A. tumefaciens with the binary vector pPZP211, a control that transferred only a gene for kanamycin resistance, provided high-level protection against TMV. Virus inoculation in these experiments was performed 2 to 3 days after infiltration, and the plants carried the $N$ gene (Whitham et al. 1994), which limits TMV infection to the production of necrotic lesions on inoculated leaves and induces the SA-dependent defense response (Gaffney et al. 1993). The unusually high level resistance to TMV was evidenced by a total absence of local lesions in the infiltrated region when leaves were inoculated with viral concentrations that caused confluent lesions and complete tissue collapse outside of the infiltrated zone (Fig. 1A). Infiltration with buffer alone provided no protection (Fig. 1A). Heatkilling the bacteria before infiltration almost completely eliminated the protective effect (Fig. 1A), showing that most of the effect requires metabolically active $A$. tumefaciens or is due to heat-sensitive elicitors. However, heat-killed A. tumefaciens retained some protection-inducing activity, consistent with ear-
A
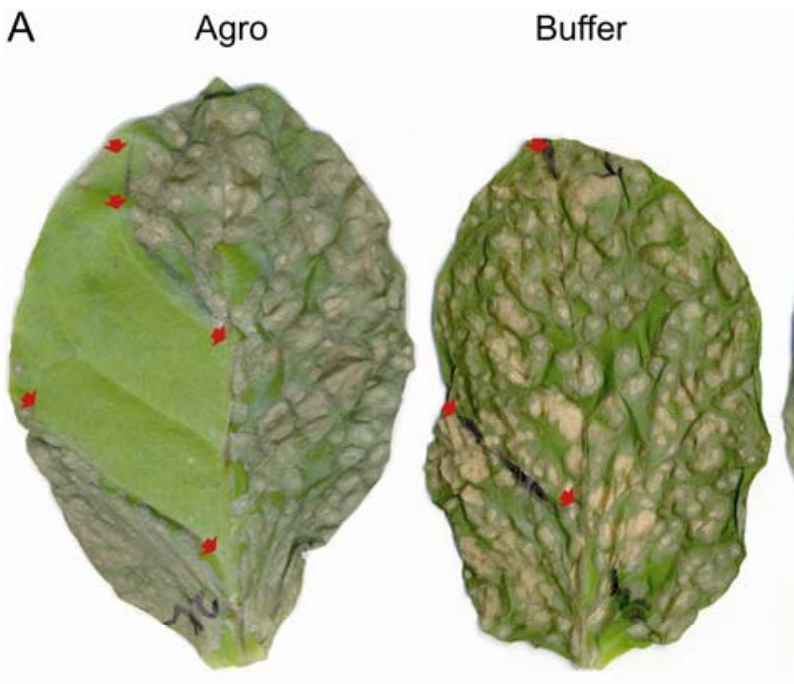

B

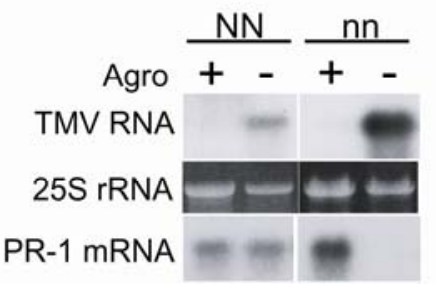

heat-killed Agro

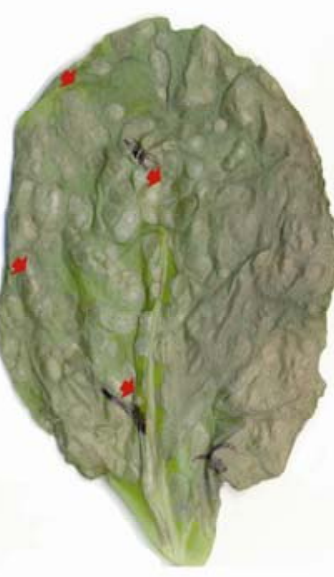

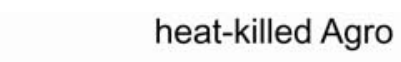

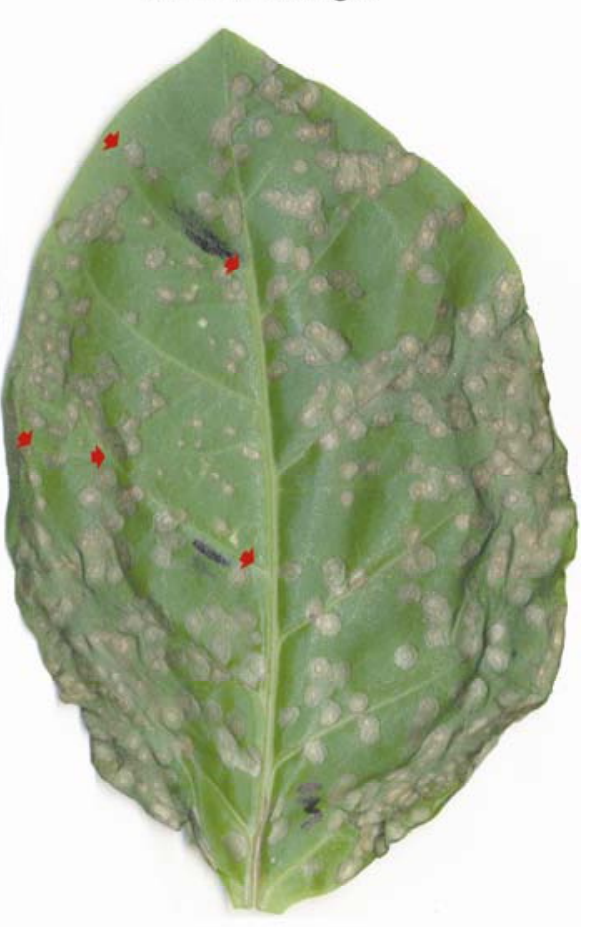

Fig. 1. Agroinfiltration induces resistance to Tobacco mosaic virus (TMV) in the infiltrated zone. Tobacco leaves were infiltrated with Agrobacterium strain ASE/pPZP211, buffer, or heat-killed ASE/pPZP211. Three days later, the entire leaf surface was inoculated with TMV. A, Leaves of $N$ gene plants were detached and scanned 4 days after TMV inoculation. Red arrows indicate the lateral vein borders of the infiltrated zones; the infiltrated zone on the buffer-infiltrated leaf extends to the leaf tip (single red arrow), and the midvein is the right border in all cases. B, Gel blot analysis of $6 \mu \mathrm{g}$ of RNA from ASE/pPZP211infiltrated (+) and noninfiltrated (-) regions of tobacco leaves from $N(\mathrm{NN})$ or non- $N$ (nn) gene plants. High molecular weight RNA was isolated from leaf tissue sampled 4 days after TMV inoculation. All samples were run on one gel and blotted onto one membrane. The blot was probed for TMV (+) strand RNA, then stripped and probed for pathogenesis-related $(P R)$ gene $P R-1$ mRNA. Full-length, genomic TMV RNA is shown. Ethidium bromide-stained $25 \mathrm{~S}$ rRNA is shown as a loading control. 
lier studies of protective responses in plants induced by heatkilled bacteria (Kelman and Sequeira 1972) and with more recent studies on heat-stable general elicitors (Felix and Boller 2003). The much lower degree of protection provided by infiltration with heat-killed A. tumefaciens was visible in leaves having relatively few lesions overall and was evidenced by the presence of TMV lesions in the infiltrated zone that were smaller than in noninfiltrated areas (Fig. 1A, far right leaf).

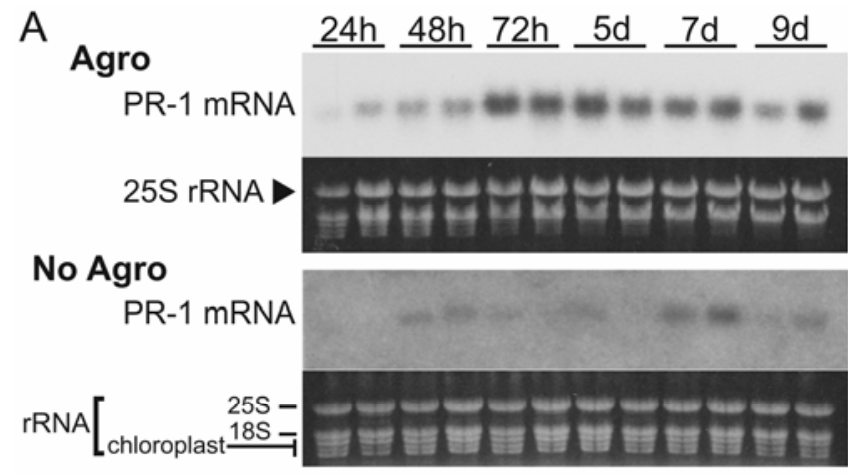

B
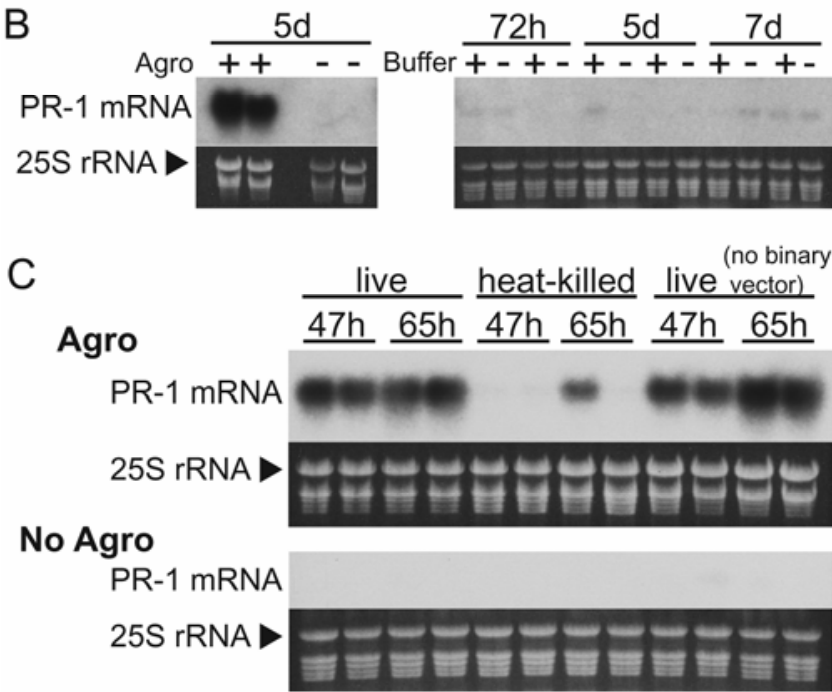

Fig. 2. Agroinfiltration alone induces pathogenesis-related $(P R)$ gene $P R-1$ expression in the infiltrated zone. High molecular weight RNA was isolated from leaf tissue sampled at the indicated times after infiltration; $10 \mu \mathrm{g}$ of each RNA was used for gel blot analysis. At each time point, two portions of two adjacent leaves on a plant were harvested, yielding four separate RNA samples per time point. One sample from each leaf was from the infiltrated zone and the other from the equivalent region on the opposite, uninfiltrated side of the midvein. A different plant was used for each time point so that equivalent leaves could be assayed throughout the experiment. All blots were probed for $P R-1$ mRNA. Ethidium bromide-stained rRNA is shown as a loading control. A, Blot and stained gel of RNA from the agroinfiltrated side of the leaves are shown in the upper (Agro) panel; the corresponding data from the uninfiltrated side of each leaf is shown directly below (No Agro). All samples were run on one gel and blotted onto one membrane. A 19-fold longer exposure of the blot is shown for the No Agro samples than for the Agro samples. Strain ASE/pPZP211 was used for infiltration. The identity of nuclear and chloroplast rRNAs visible on the stained gel is indicated for the No Agro samples; otherwise, only $25 \mathrm{~S}$ rRNA is indicated. B, Additional controls from the experiment shown in panel A. At the 5-day (5d) time point, RNA was also isolated from non-infiltrated leaf tissue (-Agro lanes) on the same side of the midvein as the agroinfiltrated region (+Agro lanes). RNA samples from buffer-infiltrated (+) and noninfiltrated (-) tissue from a single leaf are in adjacent lanes on the gel. All samples were run on one gel and blotted onto one membrane. C, Live or heat-killed ASE/pPZP211 or live ASE (no binary vector) was used for infiltration. RNA from infiltrated and corresponding noninfiltrated tissue is arranged as in panel A. All samples were run on one gel and blotted onto one membrane. Only one exposure of the blot is shown.
Gel blot analysis of RNA isolated from leaves infiltrated with A. tumefaciens and subsequently inoculated with TMV confirms that the absence of local lesions in the infiltrated zone corresponds to the absence of TMV (Fig. 1B, NN lanes) and not to inhibition of the hypersensitive response. Agroinfiltration also induced resistance to TMV in tobacco plants without the $N$ gene: No TMV RNA was detected in the infiltrated zones of leaves inoculated with TMV, whereas the uninfiltrated halves of the leaves had a high level of viral RNA (Fig. $1 \mathrm{~B}$, nn lanes). Thus, the resistance is independent of $N$ gene function, suggesting that A. tumefaciens induces a defense response effective against TMV. To investigate this possibility, we examined expression in these tissues of the gene encoding PR protein 1 (PR-1), which is strongly induced in TMV infection of plants carrying the $N$ gene and is a well-known indicator of the SA-dependent defense response (Uknes et al. 1993; Ward et al. 1991). We found that $P R-1$ was highly induced not only in the $N$-gene plants, but also in the agroinfiltrated zone of the non- $N$-gene plants (Fig. 1B). The uninfiltrated side of the leaf of non- $N$-gene plants was not highly induced for $P R-1$ (Fig. 1B), as expected for TMV infection of plants lacking the $N$ gene.

The above results suggest that agroinfiltration without subsequent TMV inoculation might induce $P R-1$. This prediction was confirmed by RNA gel blot analysis of $P R-1$ expression at different times after agroinfiltration. $P R-1 \mathrm{mRNA}$ was detectable in the infiltrated zone at low levels $24 \mathrm{~h}$ after infiltration and increased dramatically over the next 2 days, remaining highly elevated as late as 9 days after infiltration (Fig. 2A, Agro lanes). Peak levels occurred 3 to 5 days after infiltration. This time course is similar to that reported for induction of $P R-1$ by TMV in $N$-gene plants (Ward et al. 1991). Unlike induction by TMV, however, induction of $P R-1$ by agroinfiltration is strictly local: noninfiltrated tissue on the opposite half of the leaf showed only sporadic, very low-level expression of $P R-1$ that was detected after a 19-fold longer exposure of the blot (Fig. 2A, No Agro lanes). Similarly, no $P R-1$ expression was detected in noninfiltrated tissue on the same side of the midvein as the infiltrated region (Fig. 2B; compare + and Agro lanes) or in leaves above those infiltrated (data not shown). Thus, induction of $P R-1$ by agroinfiltration is limited to the infiltrated region, consistent with the absence of protection against TMV outside that zone (Fig. 1A). As expected, buffer infiltration did not induce $P R-1$. Both infiltrated and noninfiltrated tissue showed only sporadic, very low-level expression of $P R-1$ (Fig. 2B, compare + and - Buffer with +Agro lanes). Heat killing A. tumefaciens before infiltration greatly compromised but did not completely eliminate induction of $P R-1$ (Fig. 2C). A longer exposure shows that lowlevel expression of $P R-1$ was induced in all the infiltrations with heat-killed $A$. tumefaciens (data not shown), consistent with the low-level protection against TMV we observed (Fig. 1A). DNA transfer is not required for induction of $P R-1$ by agroinfiltration, because $A$. tumefaciens without a binary vector induced $P R-1$ as well as A. tumefaciens with pPZP211 (Fig. 2C).

Induction of $P R-1$ by agroinfiltration suggests that $A$. tumefaciens induces the SA-dependent defense response. To test this idea, we infiltrated leaves of $N$-gene plants expressing the $n a h G$ gene, which prevents accumulation of SA (Gaffney et al. 1993), and inoculated with TMV 3 days later. Protection against TMV in the agroinfiltrated zone was highly variable in $n a h G$ plants. Little or no protection was evident in the infiltrated regions of some leaves of nahG plants (Fig. 3, right leaf), consistent with the protection being SA dependent. In other leaves, however, protection was reduced-but not eliminated-as evidenced by smaller lesions in the infiltrated zone 
(Fig. 3, middle leaf). Because we observed complete protection in all leaves of wild-type plants, these results with $n a h G$ plants suggest that the protection against TMV induced by agroinfiltration is at least partially SA dependent.

\section{Agroinfiltration induces chlorosis and}

\section{inhibits leaf expansion in the infiltrated zone.}

During the above experiments, it became clear that resistance to TMV is only one of several readily apparent effects of infiltrating tobacco leaves with A. tumefaciens. The infiltrated zone became less green than the surrounding tissue and failed to expand in young, otherwise rapidly expanding leaves (Fig. 4A). This chlorosis and inhibition of leaf expansion were most visible in very young leaves, becoming apparent approximately 3 days after infiltration. Older leaves showed much milder chlorosis and no effect on expansion (Figs. 1A and 3); even older leaves showed no chlorosis (data not shown). Chlorosis in the infiltrated zone was accompanied by a pronounced loss of chloroplast rRNAs (Bollenbach et al. 2005) in that tissue (Fig. 2A; compare rRNAs in Agro lanes with those in No Agro lanes). Infiltration with buffer produced none of these effects (Figs. 2B and 4A). Heat-killing A. tumefaciens before infiltration largely eliminated them (Figs. 2C and 4B), indicating that they-like protection against $\mathrm{TMV}$-are due to metabolically active A. tumefaciens or heat-sensitive factors. Lastly, chlorosis and inhibition of leaf expansion were induced about as well in nahG as in wild-type plants (Fig. 4A), suggesting that these effects of agroinfiltration are independent of SA accumulation.

\section{Ti plasmid-encoded factors play a minor role in host responses elicited by infiltration with disarmed A. tumefaciens.}

The above experiments used a disarmed strain of Agrobacterium having the $\mathrm{C} 58$ chromosomal background. Although deleted of the T-DNA, disarmed Ti plasmids still encode many proteins-such as those transferred into the plant and those involved in synthesis and assembly of the T-pilus-that could potentially elicit host responses. To determine whether any of the responses described above are caused by $\mathrm{Ti}$ plasmidencoded functions, we used strain A136, which is C58 cured of its Ti plasmid. Infiltration with A136 conferred considerable protection against TMV and induced $P R-1$ expression but was less effective than our standard disarmed strain. Very small local lesions were evident in the infiltrated zone when leaves were inoculated with viral concentrations that caused confluent tissue death outside of that zone (Fig. 5A, left leaf and magnified view), and the level of $P R-1$ induction was reduced (Fig. 5B). A136 also inhibited leaf expansion and induced mild chlorosis (Fig. 5A, compare topmost leaves). Thus, infiltration with strain A136 induced effects very similar to those produced by our standard disarmed strain. These results show that Ti plasmid-encoded functions are not required to elicit the host responses but contribute to their magnitude.

The level of induction of $P R-1$ and protection against TMV produced by infiltration with heat-killed $A$. tumefaciens or with the $\mathrm{Ti}$ plasmid-less strain A136 often varied considerably from leaf to leaf, making calculation of an average value not very meaningful. However, another way of analyzing the data is to compare the fraction of samples in each group that gave a response roughly comparable with that produced by our standard disarmed strain, ASE/pPZP211. In tobacco without the $n a h G$ gene, non-heat killed ASE/pPZP211 always gave strong induction of $P R-1$ as well as complete protection against TMV at the viral concentrations used in these experiments. Therefore, for all strains and manipulations used in this study, we have calculated the fraction of samples that showed $P R-1$ induction roughly comparable with that of nonheat killed ASE/pPZP211 (Table 1). This analysis supports the conclusion that A136 is mildly defective and heat-killed $A$. $t u$ mefaciens greatly but not totally defective for inducing host responses.

An interesting question is whether the suite of responses characterized above is specific to A. tumefaciens or reflects a
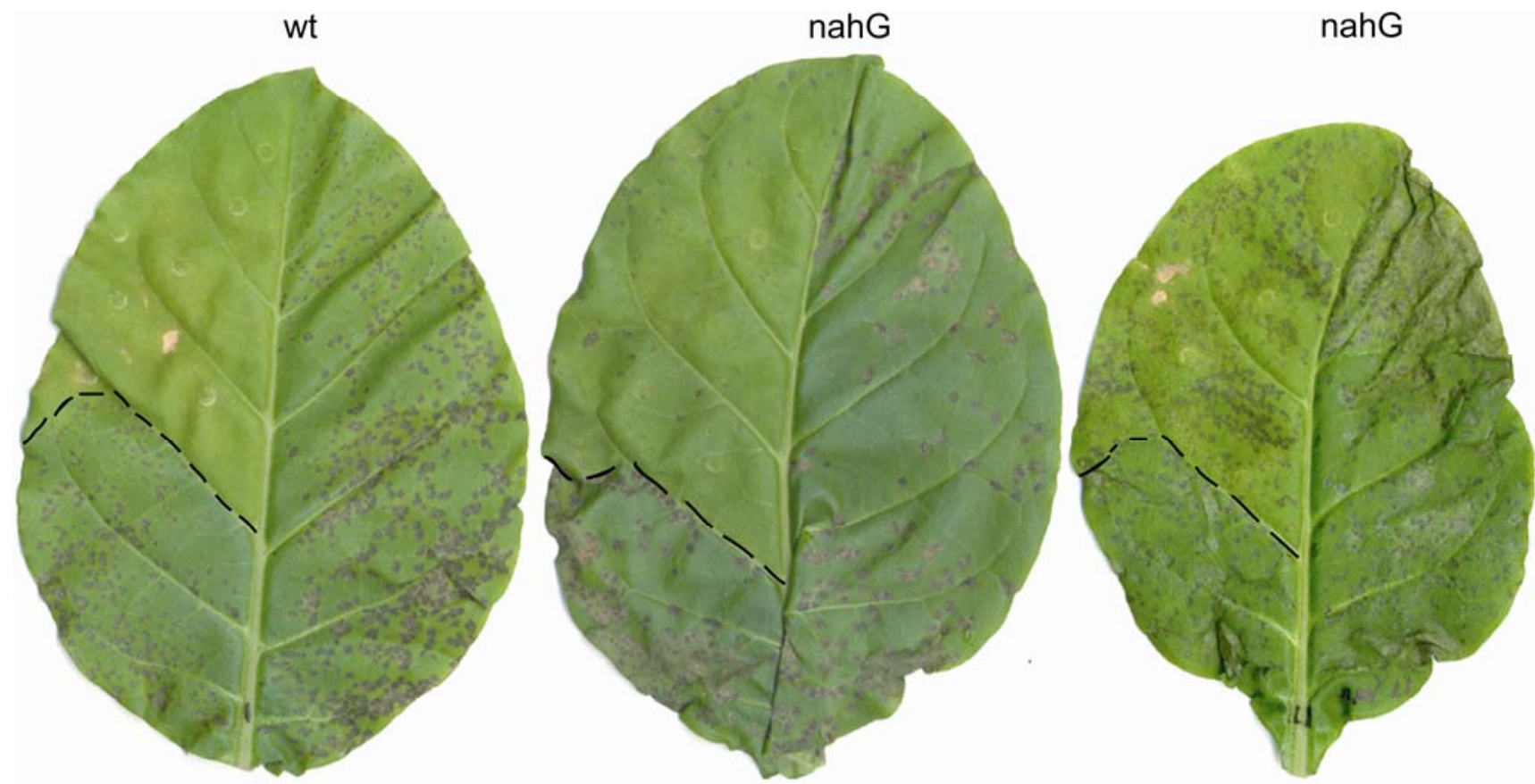

Fig. 3. Expression of nahG partially compromises resistance to Tobacco mosaic virus (TMV) induced by agroinfiltration. Leaves were infiltrated with ASE/pPZP211. The infiltrated zone includes the left half of the leaf from the tip to the lateral veins indicated by black dashes. Leaves were detached and scanned 3 days (right leaf) or 4 days (left and center leaves) after inoculation with TMV. The right leaf was scanned early because parts of the uninfiltrated side of the leaf had started to collapse and die. 
general response to bacteria. Considerable evidence suggests that defense signaling initiated by different general elicitors converges to produce similar downstream effects (He et al. 2007). Consistent with this picture, defense and stress-related genes that were induced by A. tumefaciens in a gene expression profiling study were also found to be induced by $E$. coli, a non-plant pathogen (Ditt et al. 2001). We found that infiltrat- ing tobacco leaves with E. coli (strains DH5 or DH5 $\alpha$ ) produced effects that were very similar to those induced by agroinfiltration. The regions infiltrated with $E$. coli were protected against TMV infection and showed mild chlorosis, inhibition of leaf expansion, and induction of $P R-1$ (data not shown; Table 1). However, chlorosis and $P R-1$ induction were attenuated relative to that produced by agroinfiltration (data not shown;
A

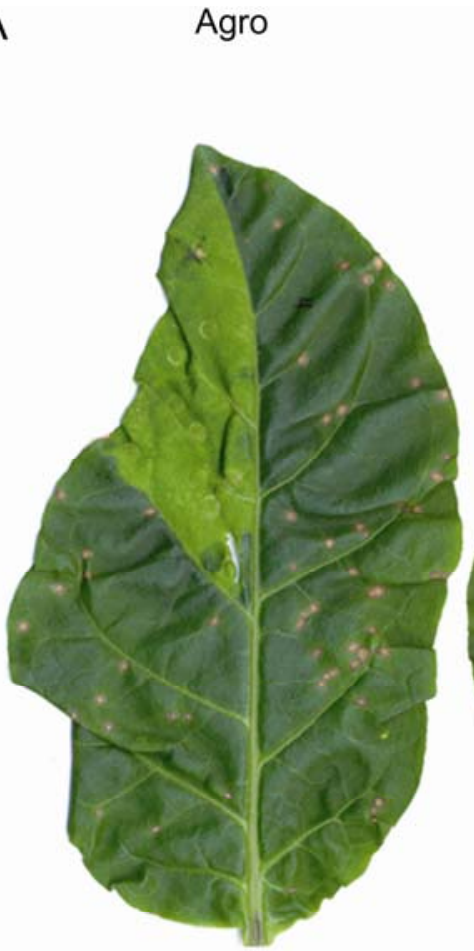

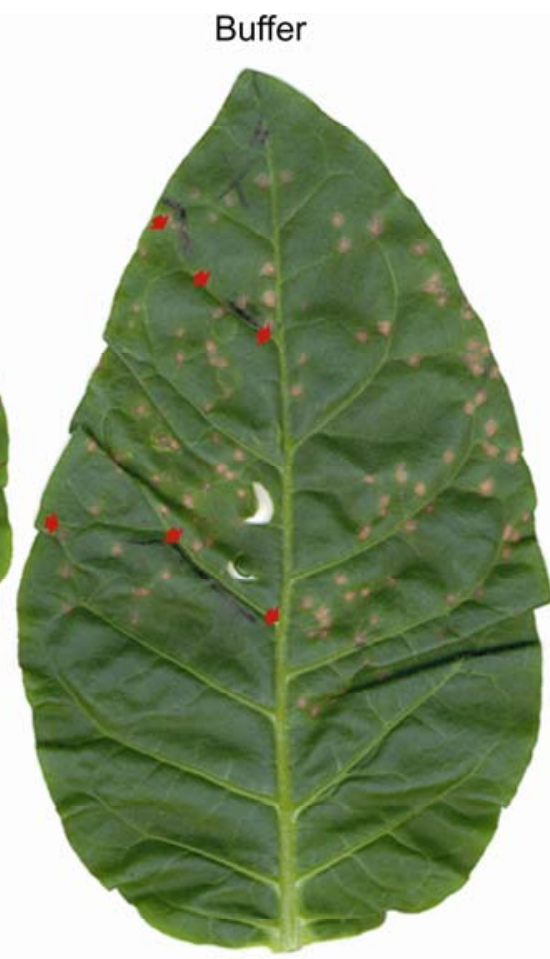

Agro

nahG plant

B
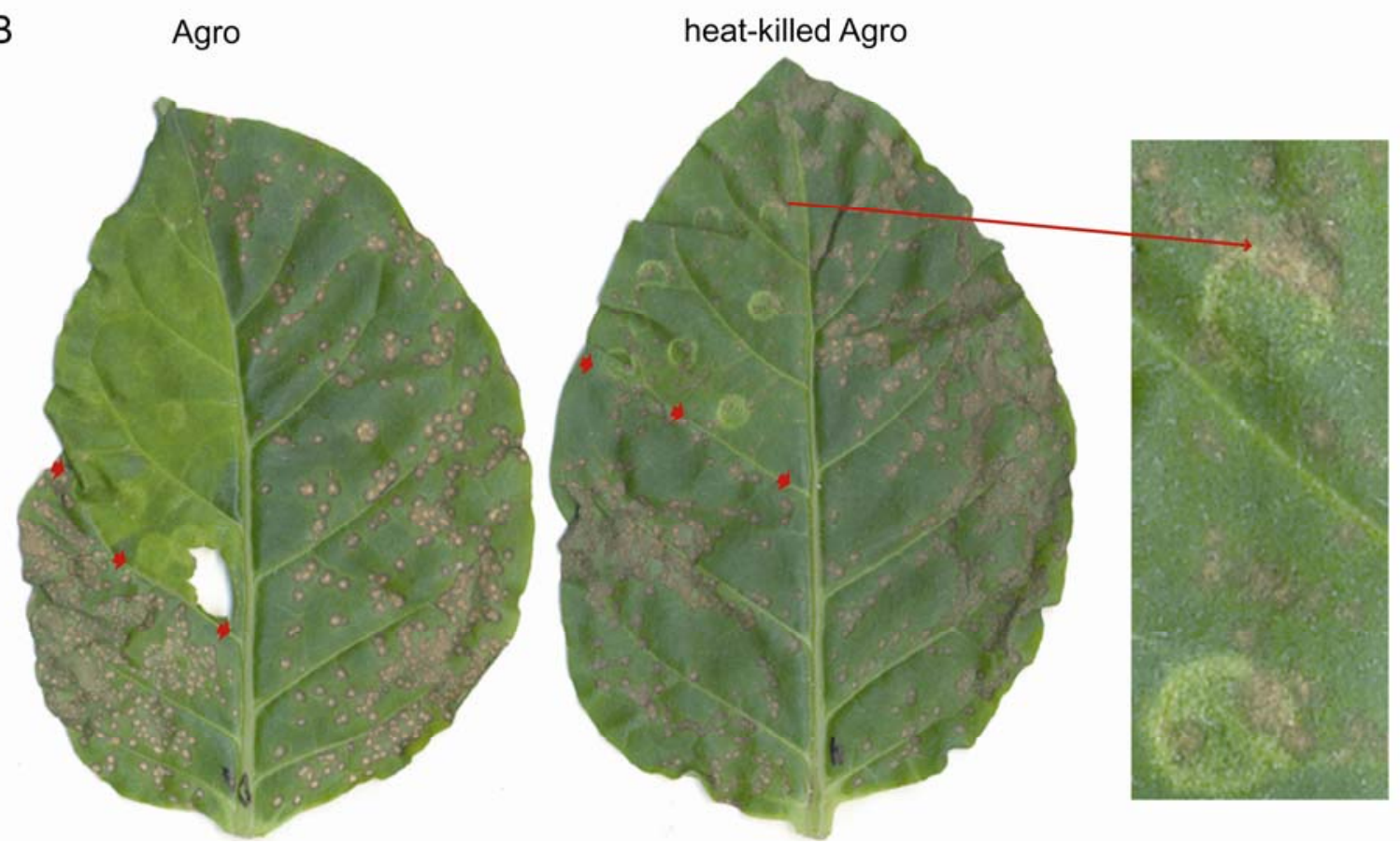

Fig. 4. Agroinfiltration induces chlorosis and inhibits leaf expansion in the infiltrated zone. Small, young leaves were infiltrated to the left of the midvein with ASE/pPZP211; Tobacco mosaic virus (TMV) inoculations were done 3 days later. These leaves are difficult to infiltrate, resulting in occasional small tears and areas that escape infiltration. Leaves were detached and scanned 7 days after infiltration. A, Comparison of agro- and buffer-infiltrated leaves. The lateral veins forming the upper and lower borders of the infiltrated zone on the buffer-infiltrated leaf are indicated by red arrows. Neither the base of that leaf nor any of the leaf of the $n a h G$ plant was inoculated with TMV. B, Comparison of agro- and heat-killed agro-infiltrated leaves. Infiltrated zones extend to the tip of the leaf. Red arrows indicate the lower border of the infiltrated zones; the magnified view shows small local lesions. 
Table 1). In contrast to A. tumefaciens, E. coli produced chlorosis even when it was heat killed (data not shown), suggesting that different elicitors are responsible for the similar host responses produced by these two different types of bacteria.

\section{T-DNA-encoded factors enhance chlorosis and prevent inhibition of leaf expansion.}

The experiments presented thus far (Figs. 1 through 5) used nononcogenic strains of Agrobacterium. In experiments using two different oncogenic strains, we observed that infiltration with oncogenic Agrobacterium strains induced much more pronounced chlorosis than infiltration with our standard disarmed strain (data not shown), suggesting that T-DNAencoded factors enhance chlorosis. However, our standard disarmed strain and those oncogenic strains had different Ti plasmids and, consequently, differed by more than simply the T-

DNA. Therefore, to specifically examine the effect of the TDNA on chlorosis, we infiltrated young leaves with C58, which harbors its native pTiC58, or with the disarmed C58 strain carrying pTiC58 $\Delta$ T-DNA. Infiltration with this disarmed strain induced effects similar to those produced by our standard disarmed strain (Fig. 6A; data not shown). Furthermore,

Table 1. Fraction of samples with high-level induction of pathogenesisrelated $(P R)$ gene $P R-1$

\begin{tabular}{lc}
\hline Infiltration & Induced/total \\
\hline ASE, ASE/pPZP211, C58 & $36 / 36$ \\
A136 & $9 / 10$ \\
Heat-killed ASE/pPZP211 & $1 / 6$ \\
Buffer & $0 / 6$ \\
Escherichia coli $(\mathrm{DH} 5$ or DH5 $\alpha)$ & $11 / 20$ \\
\hline
\end{tabular}

A

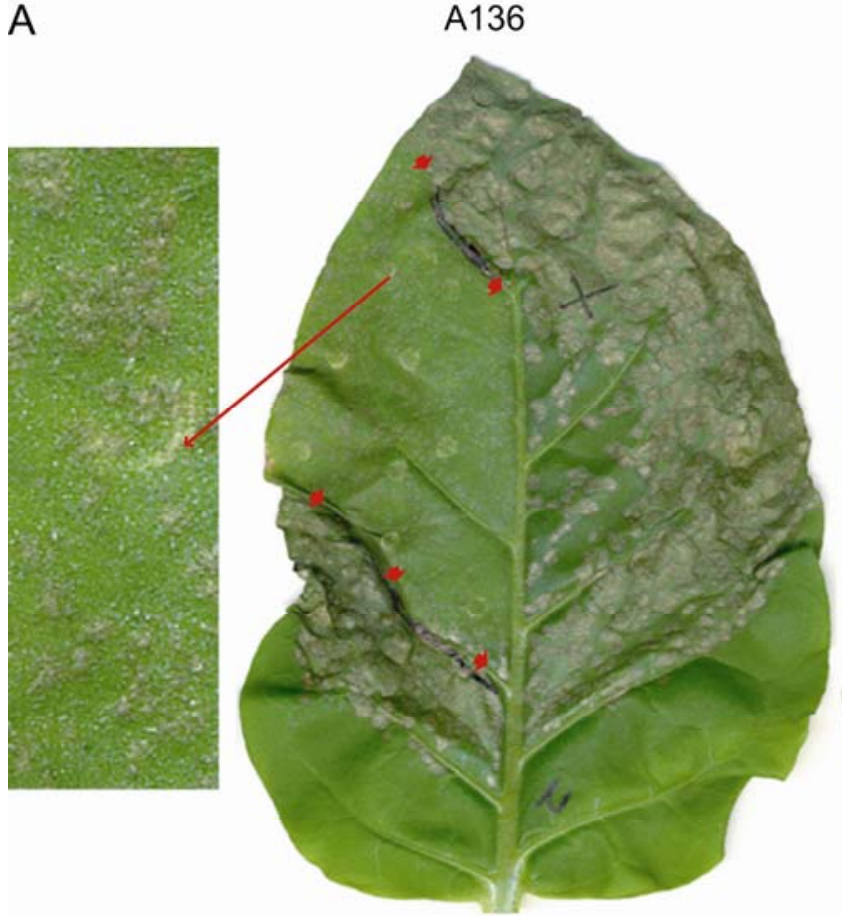

B

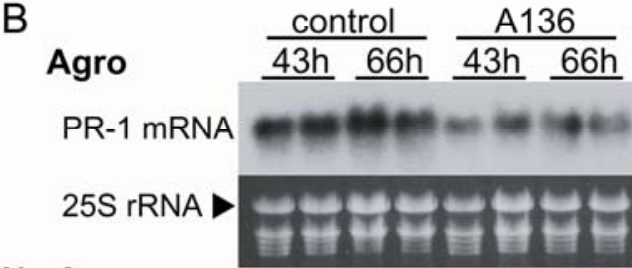

No Agro

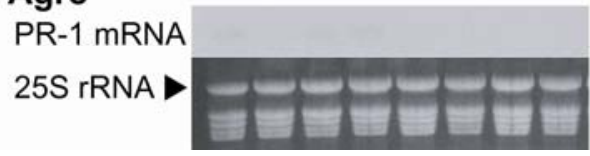

A136

control

(ASE)

pPZP211)

topmost

topmost
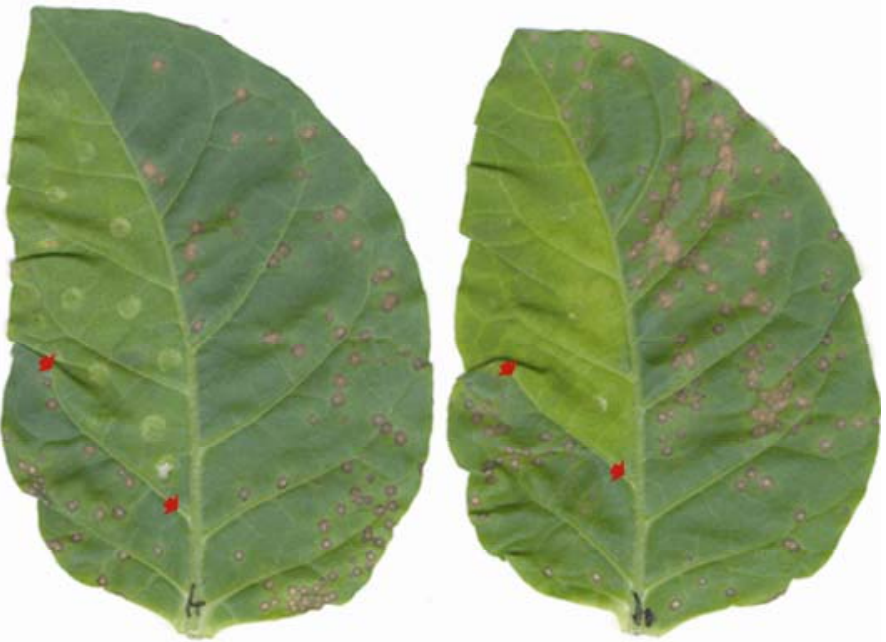

Fig. 5. Ti plasmid-encoded factors contribute slightly to the effects induced by infiltration with disarmed Agrobacterium tumefaciens. Leaves were infiltrated to the left of the midvein using the strains indicated; Tobacco mosaic virus (TMV) inoculations were done 3 days later. Leaves were scanned 7 days after infiltration. A, The Ti plasmid-less strain A136 and an ASE/pPZP211 control. Infiltrated zones extend to the tip of the leaf in the case of the topmost leaves; red arrows indicate the lower border of the infiltrated zones on those leaves and both the upper and lower borders on the remaining leaf. The magnified view shows small local lesions; the bottom portion of this leaf was not inoculated with TMV. The right two leaves were small, young (topmost) ones when infiltrated. B, Induction of pathogenesis-related $(P R)$ gene $P R-1$ expression by Ti plasmid-less strain A136 compared with an ASE/pPZP211 control. At each timepoint, two adjacent leaves on a plant were sampled in infiltrated and noninfiltrated zones for isolation of high molecular weight RNA; $10 \mu \mathrm{g}$ of each RNA was used for gel blot analysis. Separate plants were used for each strain and timepoint. Upper (Agro) panel shows the blot and stained gel of RNA from the agroinfiltrated side of the leaves; the corresponding data from the uninfiltrated side of each is shown directly below (No Agro). All samples were run on one gel and blotted onto one membrane. Only one exposure of the blot is shown. 
infiltration with $\mathrm{C} 58$ induced $P R-1$ expression and protection against TMV comparable with that produced by disarmed strains (Table 1; data not shown). In contrast, infiltration with C58 induced much more pronounced chlorosis and, surprisingly, failed to inhibit leaf expansion (Fig. 6A). At $68 \mathrm{~h}$ after infiltration, when chlorosis and inhibition of leaf expansion start to become evident, there is little apparent difference between the effects of these oncogenic and disarmed strains. At later times, however, there is a clear enhancement of chlorosis and failure to inhibit leaf expansion in the C58-infiltrated region compared with the $\triangle \mathrm{T}$-DNA control. Thus, T-DNAencoded factors alter some host responses to A. tumefaciens.

\section{T-DNA-encoded factors enhance accumulation} of a microRNA that represses auxin signaling and contributes to antibacterial resistance.

Recent studies have linked changes in accumulation of miRNAs that repress auxin signaling to both Agrobacteriuminduced tumorigenesis and bacterial elicitor induction of plant defense. Accumulation of miR393 and miR167 are greatly re- duced in C58-induced tumors (Dunoyer et al. 2006). In contrast, increased accumulation of miR393 is associated with plant defense (Navarro et al. 2006). To see whether these responses occur in agroinfiltrated tissue, we examined miRNA accumulation in the leaves shown in Figure 6A. We made three separate groups of measurements to compare accumulation of miRNA in the infiltrated and noninfiltrated regions of the leaves (Fig. 6B). Although the three groups correspond to three different times after infiltration, our intent in this experiment was only to compare miRNA levels in infiltrated and noninfiltrated tissue, not to determine the time course of miRNA accumulation. The data shown in Figure $6 \mathrm{~B}$ correspond to three separate gels and blots, and the blots were processed separately from one another. Consequently, only comparisons within each blot can be made. The data show that infiltration with disarmed C58 had little effect on miR393 accumulation but, unexpectedly, tissue infiltrated with the oncogenic strain had increased levels of miR393 (Fig. 6B). In each of five plants, the level of miR393 in C58-infiltrated leaf tissue was increased relative to that in the uninfiltrated portion

A

C58

$\triangle \mathrm{T}$-DNA

C58
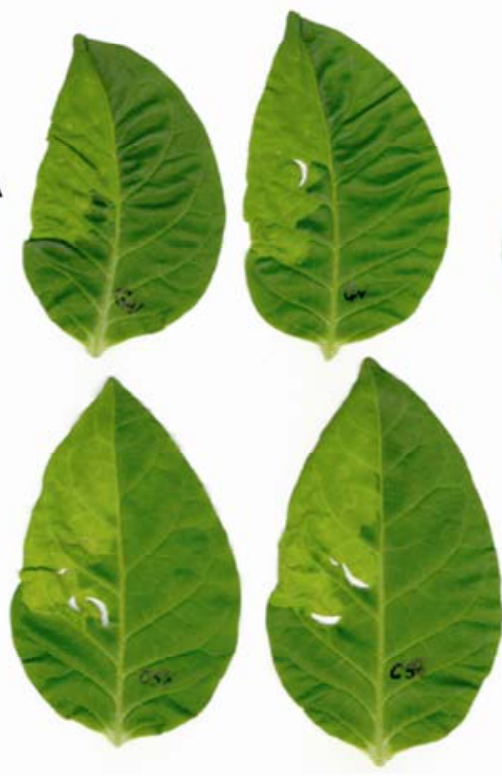

$68 \mathrm{~h}$

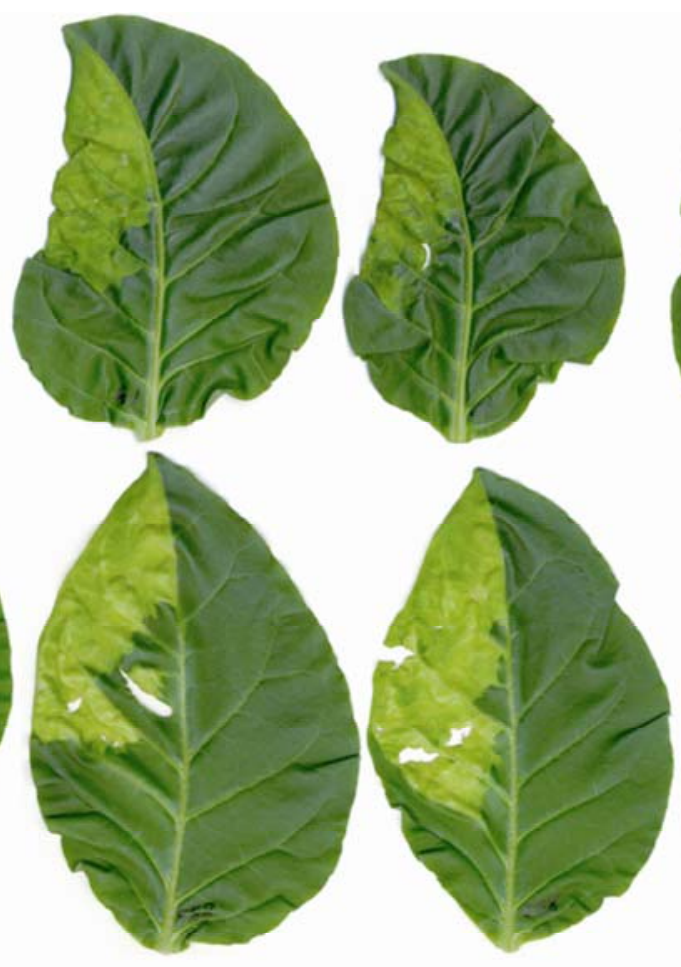

$8 d$

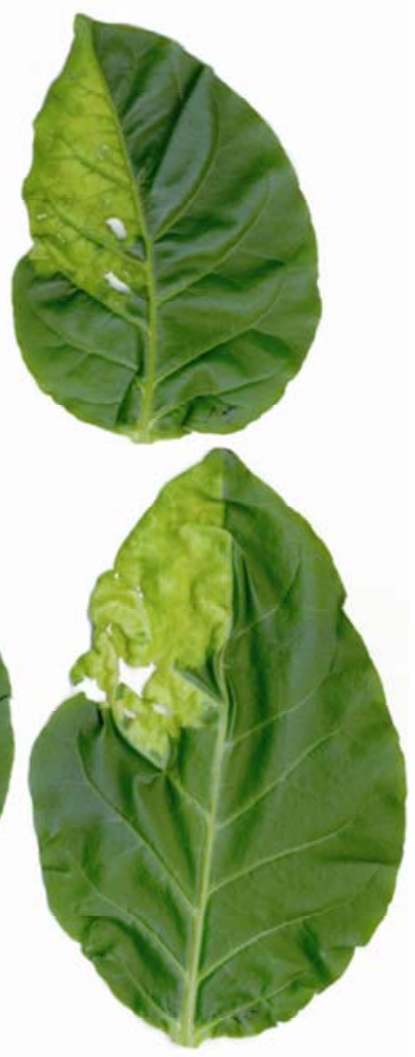

$13 d$
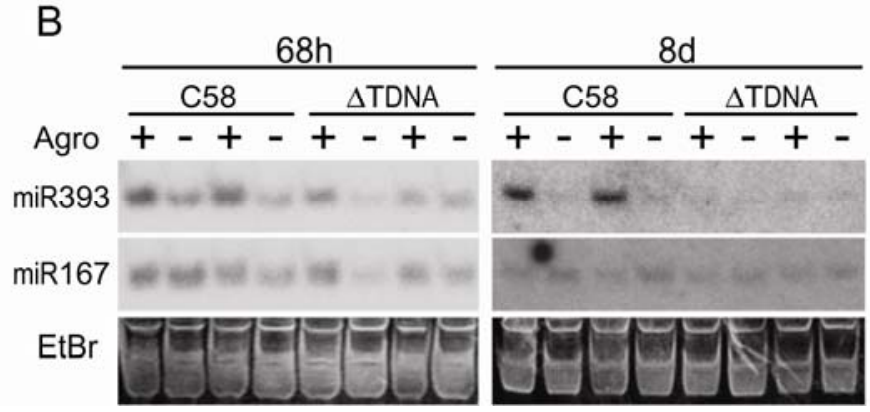

$13 d$
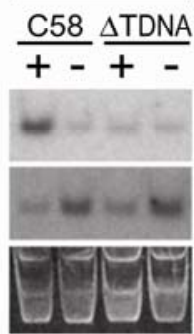

Fig. 6. T-DNA-encoded factors alter some host responses to agroinfiltration. A, Small, young leaves were infiltrated to the left of the midvein with C58 (bottom row) or GV3101::PMP90 (= C584T-DNA, top row). The topmost infiltrated leaf from each of 10 plants is shown; leaves were detached and scanned at the times indicated. B, Accumulation of miR393 and miR167 in agroinfiltrated and noninfiltrated regions of the leaves shown in panel A. Total RNA was isolated from tissue harvested immediately after leaves were scanned; $10 \mu \mathrm{g}$ of each sample was used for gel blot analysis. All samples harvested at the same time after infiltration were run on one gel and blotted onto one membrane. Blots were probed for miR393, then stripped and probed for miR167. Ethidium bromide (EtBr)-stained RNA is shown as a loading control. 
of the leaf. In contrast, miR393 accumulation in leaf tissue of five plants infiltrated with disarmed C58 was about the same as in uninfiltrated controls, except for one of the earliest samples. The increase in miR393 accumulation in C58-infiltrated tissue appears specific to miR393 because miR167 accumulation was not affected similarly (Fig. 6B). Interestingly, increased accumulation of miR393 in C58-infiltrated tissue has the potential to both counter increased levels of auxin and reduce the susceptibility of the plant to oncogenic A.tumefaciens,

\section{The fate of $A$. tumefaciens infiltrated into leaves.}

How well different strains of Agrobacterium grow and multiply after infiltration is a factor that could lead to differences in host responses to the different strains. For this reason, we assayed infiltrated zones to determine the concentration of CFU of A. tumefaciens as a function of time after infiltration. Surprisingly, none of the strains we infiltrated showed an increase in colony-forming units (CFU) after infiltration (Fig. 7) - perhaps because of the high concentration of bacteria used for infiltration (approximately $8 \times 10^{8} \mathrm{CFU} / \mathrm{ml}$ ). All of the strains showed a marked drop in CFU over the time course of our experiments. The two Ti plasmid-less strains we tested (Fig. 7 and data not shown) showed the least drop in CFU of all the strains, resulting in the highest level of CFU in planta of all the strains tested. Because the Ti plasmid-less strain A136 is slightly defective for inducing the host responses we have characterized (Fig. 5), this result indicates that the concentration of viable bacteria in the plant is less important for induction of these responses than the biological activity of the bacteria. Surprisingly, the oncogenic strain C58 had the lowest concentration in planta of the strains we assayed. Initially and at 2 days after infiltration, the concentration of C58 in leaves was approximately sixfold lower than that of the corresponding disarmed strain (Fig. 7). Because increased effects on the host are associated with increased $A$. tumefaciens concentration (Yuan et al. 2007), we consider that reduced bacterial concentration compared with the disarmed control is unlikely to be responsible for the increased effect of C58 on chlorosis and miR393 accumulation (Fig. 6A and B). However, reduced bacterial concentration might account for the failure of C58 to inhibit leaf expansion (Fig. 6A).

\section{DISCUSSION}

The present study shows that infiltrating leaves of intact tobacco plants with disarmed or oncogenic A. tumefaciens induces expression of $P R-1$ and provides protection against subsequent TMV infection in the infiltrated zone (Figs. 1 and 2; Table 1; data not shown). These results suggest that $A$. tumefaciens induces the SA-dependent defense pathway within the infiltrated region. Consistent with this idea, nahG plants, which are defective for accumulation of SA, were compromised for the protection against TMV induced by A. tumefaciens (Fig. 3). The protection was only partially compromised, however, suggesting that SA-independent components might also be involved. Alternatively, this result might simply reflect the fact that accumulation of SA and induction of $P R$ genes is not completely eliminated in nahG plants (Friedrich et al. 1995). During the course of the present study, another group noted that their agroinfiltrated Nicotiana benthamiana control was induced for $P R-1$ expression (Ludwig et al. 2005).

Activation of the SA signaling pathway and induction of $P R-1$ expression occur in response to various stresses (Fujita et al. 2006; Strawn et al. 2007; van Loon et al. 2006) as well as in host defense. We cannot rule out the possibility that these effects of agroinfiltration reflect a response to stress as opposed to a defense response; however, two recent studies support the host defense response interpretation. In the first, A. tumefaciens was found to upregulate the $P R-1$ promoter by activating a host transcription factor via the MAP kinase defense-signaling pathway (Djamei et al. 2007). That work provides strong evidence that $P R-1$ induction is a host defense response to $A$. $t u$ mefaciens and provides a likely mechanism for the induction of $P R-1$ by agroinfiltration. In the second study, the SA-dependent defense pathway was shown to protect against infection with A. tumefaciens (Anand et al. 2008).

A. tumefaciens also induces chlorosis, loss of chloroplastencoded rRNAs, and inhibition of leaf expansion in the infiltrated zone of young leaves (Fig. 2A and 4A). These responses do not appear to be SA dependent, and it remains to be determined whether they are related to defense. However, chlorosis is a common response of plants to pathogens, and repression of genes involved in chlorophyll biosynthesis has been shown to occur in response to bacteria whether or not they have functional hrp genes (Truman et al. 2006). The oncogenic strain C58 produced enhanced chlorosis but, unexpectedly, did not inhibit leaf expansion (Fig. 6A). Absence of an effect on leaf expansion by C58 might reflect its lower concentration in planta compared with the disarmed control (Fig. 7). Because A. tumefaciens-induced tumors have reduced chlorophyll content, fewer chloroplasts, and reduced expression of chloro-

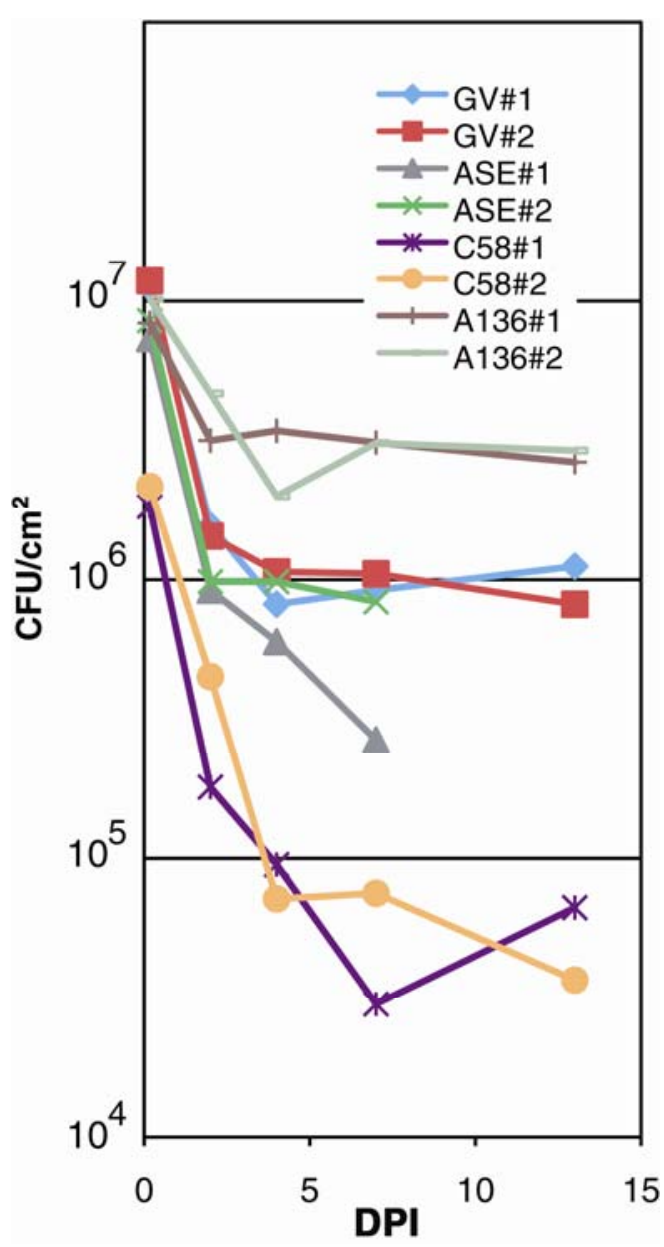

Fig. 7. Concentration of Agrobacterium tumefaciens in planta drops off after infiltration. Leaves of two plants each were infiltrated with the indicated strains of Agrobacterium and assayed at subsequent times to determine the concentration of viable bacteria in the infiltrated zones as a function of days post infiltration (DPI). The initial samples were taken at 3.5 to $4 \mathrm{~h}$ after infiltration. The designations \#1 and \#2 denote the individual plants used for each strain. The abbreviation GV denotes strain GV3101:: PMP90 and ASE denotes ASE/pPZP211. 
plast-encoded genes (Deeken et al. 2006), we expect that chlorosis and loss of chloroplast rRNAs in tissue infiltrated with $A$. tumefaciens are components of the natural host response to this pathogen.

In Arabidopsis, accumulation of miR393 and miR167 is greatly reduced in A. tumefaciens-induced tumors compared with normal tissue (Dunoyer et al. 2006). Our experiments examine tissue at much earlier times than that study and show that miR393, but not miR167, is increased in tobacco leaves infiltrated with oncogenic A. tumefaciens (Fig. 6B). This increase in accumulation of miR393 is not simply a nonspecific response to bacteria because it does not occur in tissue infiltrated with the disarmed control (Fig. 6B). Repression of auxin signaling by miR393 was recently reported to be responsible for the increase in antibacterial resistance caused by perception of bacterial flagellin (Navarro et al. 2006). In that study, treatment of Arabidopsis seedlings with an elicitor-active peptide of flagellin increased accumulation of miR393 relative to treatment with the corresponding peptide from A. tumefaciens, which does not have elicitor activity (Felix et al. 1999; Gomez-Gomez et al. 1999). However, oncogenic A. tumefaciens has a mechanism independent of general elicitors that could potentially lead to increased accumulation of miR393 in plants: increased auxin biosynthesis due to transfer and expression of the T-DNA genes. Increased accumulation of miR393 in tissue infected by oncogenic A. tumefaciens might be a homeostatic mechanism that does double duty as a defense response. The observation that miR393 accumulation initially increases in tissue infiltrated with oncogenic A. tumefaciens (Fig. 6B) but is greatly reduced in tumor tissue (Dunoyer et al. 2006) raises the interesting possibility that successful transformation involves turning off this host response.

Agroinfiltration is a popular technique for transient expression and for inducing silencing, and the protocol used in the present work is a typical one. Whether or not the responses reported here are ones that occur under natural conditions of infection, they are ones that occur in experiments using standard agroinfiltration protocols in N. tabacum. Other stress- and defense-related responses have recently been shown to occur in grapevine leaves in response to infiltration with $A$. tumefaciens (Santos-Rosa et al. 2008). Thus, responses induced by $A$. tumefaciens are not negligible and have the potential to interfere with or complicate the interpretation of experiments that use agroinfiltration. A case in point is the experiment that initiated the work reported here. We wanted to determine whether the enhanced resistance to TMV observed in P1/HC-Pro transgenic plants at temperatures permissive for $N$ gene function (Pruss et al. 2004) could be reproduced in a transient expression system. Instead, we found that agroinfiltration itself protects against TMV infection. The present study dramatically illustrates that even disarmed strains of Agrobacterium are not simply neutral agents of gene transfer.

\section{MATERIALS AND METHODS}

\section{Plants and pathogens.}

Experiments were performed in N. tabacum cv. Xanthi NN with the following exceptions. The non- $N$ gene line (Fig. 1B) was $N$. tabacum cv. Xanthi nn, plants used for the experiment in Figure 3 were the vector-transformed control and $n a h G \times$ control lines of $N$. tabacum cv. Havana 425 described previously (Pruss et al. 2004), and another $n a h G$ line used (Fig. 4A) was $n a h G \times N$. tabacum cv. Xanthi nn. The same parental $n a h G$ line was used in both crosses. TMV was the common strain, American Type Culture Collection PV-135, and the virus stock was sap from inoculated leaves of $N$. clevelandii.
All Agrobacterium strains used have the C58 chromosomal background. Disarmed strains were ASE, which is A208 with pTiT37SE (Rogers et al. 1987), and GV3101::pMP90, which has pTiC58 $\Delta$ T-DNA (Hellens et al. 2000). Other strains were C58 (Hamilton and Fall 1971) and A136, which is C58 cured of pTiC58 (Hellens et al. 2000). Unless indicated otherwise, agroinfiltration was performed using ASE carrying the binary vector pPZP211 (Hajdukiewicz et al. 1994).

\section{Agroinfiltration and virus inoculation.}

Preparation of $A$. tumefaciens was largely as described (Llave et al. 2000). Briefly, overnight cultures were grown at $29^{\circ} \mathrm{C}$ in Luria-Bertani (LB) medium plus appropriate antibiotics, subcultured into fresh medium (LB, 10 mM MES, pH 6.0, acetosyringone at $20 \mu \mathrm{g} / \mathrm{ml}$, and appropriate antibiotics), and grown with good aeration at $29^{\circ} \mathrm{C}$ to optical density at $595 \mathrm{~nm}$ $\left(\mathrm{OD}_{595}\right)=1$ to 1.8 . Cells were harvested by centrifugation, resuspended in buffer $(10 \mathrm{mM} \mathrm{MgCl} 2,10 \mathrm{mM}$ MES, pH 5.6, and $150 \mu \mathrm{M}$ acetosyringone) to $\mathrm{OD}_{595}=1.0$ (approximately $8 \times$ $10^{8} \mathrm{CFU} / \mathrm{ml}$ ) and kept at room temperature for approximately $5 \mathrm{~h}$. To kill A. tumefaciens, an aliquot of resuspended cells was heated at 67 to $70^{\circ} \mathrm{C}$ for 30 to $60 \mathrm{~min}$, then cooled at room temperature. No colonies were obtained from plating $0.1 \mathrm{ml}$ of heated cells. Preparation of E. coli for infiltration was exactly as described above for $A$. tumefaciens

Plants were grown at 23 to $26^{\circ} \mathrm{C}$ and used 4 to 6 weeks after germination. Initial experiments used a growth chamber with $16 \mathrm{~h}$ of light; later experiments were performed using $24 \mathrm{~h}$ of light. No difference was observed between these two regimens. Leaves were evenly infiltrated throughout a large zone on onehalf of the leaf using a 1-ml needleless syringe applied to the underside of the leaf. Infiltrated zone boundaries were a lower lateral vein, the midvein, the edge of the leaf, and either the leaf tip or an upper lateral vein. Imprints of the syringe were often visible (Fig. 4B). Only one strain of Agrobacterium was used per plant, and three to six adjacent leaves were infiltrated. In experiments that used TMV, leaves were mechanically inoculated with virus 3 days after infiltration. To quantitate the concentration of A. tumefaciens in leaves, a punch was used to excise three leaf discs from an infiltrated region and the discs were ground in a microcentrifuge tube using a plastic pestle. Then, $1 \mathrm{ml}$ of LB was added, the sample was vigorously vortexed for a minute, and appropriate dilutions were plated immediately.

\section{RNA isolation and hybridization.}

Leaf samples $(0.25$ to $0.30 \mathrm{~g})$ were immediately frozen in liquid nitrogen and stored at $-70^{\circ} \mathrm{C}$. Frozen leaf tissue was ground in liquid nitrogen; then high molecular weight (HMW) RNA was isolated as described (Mlotshwa et al. 2005), with minor modifications, or total RNA was isolated using TRI Reagent (Sigma-Aldrich) according to the manufacturer, with minor modifications. RNA gel blot analysis of HMW RNA and miRNA was performed as described (Mallory et al. 2002; Vance 1991) using Ambion ULTRAhyb or ULTRAhyb-Oligo hybridization solution, respectively, at $42^{\circ} \mathrm{C}$. All probes were ${ }^{32} \mathrm{P}$-labeled. Probes to TMV and to tobacco $P R-1 a$ were prepared as described (Pruss et al. 2004); miRNA probes were made by end-labeling antisense oligonucleotides with T4 polynucleotide kinase (New England Biolabs).

\section{ACKNOWLEDGMENTS}

We thank L. Bowman and J. Stratmann for helpful comments on the manuscript. This work was supported by National Institute of Health Grant GM6101401 and National Science Foundation (NSF) Grant 0501760 to V. Vance, and NSF Grant MCB-9723735 and U.S.-Israel Binational Agricul- 
tural Research and Development Research (BARD) Research Grant IS3622-04R to E. W. Nester.

\section{LITERATURE CITED}

Anand, A., Uppalapati, S. R., Ryu, C. M., Allen, S. N., Kang, L., Tang, Y., and Mysore, K. S. 2008. Salicylic acid and systemic acquired resistance play a role in attenuating crown gall disease caused by Agrobacterium tumefaciens. Plant Physiol. 146:703-715.

Bollenbach, T. J., Lange, H., Gutierrez, R., Erhardt, M., Stern, D. B., and Gagliardi, D. 2005. RNR1, a 3'-5' exoribonuclease belonging to the RNR superfamily, catalyzes $3^{\prime}$ maturation of chloroplast ribosomal RNAs in Arabidopsis thaliana. Nucleic Acids Res. 33:2751-2763.

Bonnet, E., Van de Peer, Y., and Rouze, P. 2006. The small RNA world of plants. New Phytol. 171:451-468.

Chisholm, S. T., Coaker, G., Day, B., and Staskawicz, B. J. 2006. Host-microbe interactions: Shaping the evolution of the plant immune response. Cell 124:803-814.

Deeken, R., Engelmann, J. C., Efetova, M., Czirjak, T., Müller, T., Kaiser, W. M., Tietz, O., Krischke, M., Mueller, M. J., Palme, K., Dandekar, T., and Hedrich, R. 2006. An integrated view of gene expression and solute profiles of Arabidopsis tumors: A genome-wide approach. Plant Cell $18: 3617-3634$

Ditt, R. F., Nester, E. W., and Comai, L. 2001. Plant gene expression response to Agrobacterium tumefaciens. Proc. Natl. Acad. Sci. U.S.A. 98:10954-10959.

Ditt, R. F., Kerr, K. F., de Figueiredo, P., Delrow, J., Comai, L., and Nester, E. W. 2006. The Arabidopsis thaliana transcriptome in response to Agrobacterium tumefaciens. Mol. Plant-Microbe Interact. 19:665-681.

Djamei, A., Pitzschke, A., Nakagami, H., Rajh, I., and Hirt, H. 2007. Trojan horse strategy in Agrobacterium transformation: Abusing MAPK defense signaling. Science 318:453-456.

Dunoyer, P., Himber, C., and Voinnet, O. 2006. Induction, suppression and requirement of RNA silencing pathways in virulent Agrobacterium tumefaciens infections. Nat. Genet. 38:258-263.

Escobar, M. A., and Dandekar, A. M. 2003. Agrobacterium tumefaciens as an agent of disease. Trends Plant Sci. 8:380-386.

Eulgem, T. 2005. Regulation of the Arabidopsis defense transcriptome. Trends Plant Sci. 10:71-78.

Felix, G., and Boller, T. 2003. Molecular sensing of bacteria in plants. The highly conserved RNA-binding motif RNP-1 of bacterial cold shock proteins is recognized as an elicitor signal in tobacco. J. Biol. Chem. 278:6201-6208

Felix, G., Duran, J. D., Volko, S., and Boller, T. 1999. Plants have a sensitive perception system for the most conserved domain of bacterial flagellin. Plant J. 18:265-276.

Friedrich, L., Vernooij, B., Gaffney, T., Morse, A., and Ryals, J. 1995. Characterization of tobacco plants expressing a bacterial salicylate hydroxylase gene. Plant Mol. Biol. 29:959-968.

Fujita, M., Fujita, Y., Noutoshi, Y., Takahashi, F., Narusaka, Y., YamaguchiShinozaki, K., and Shinozaki, K. 2006. Crosstalk between abiotic and biotic stress responses: A current view from the points of convergence in the stress signaling networks. Curr. Opin. Plant Biol. 9:436-442.

Gaffney, T., Friedrich, L., Vernooij, B., Negrotto, D., Nye, G., Uknes, S., Ward, E., Kessmann, H., and Ryals, J. 1993. Requirement of salicylic acid for the induction of systemic acquired resistance. Science 261:754756.

Gaspar, Y. M., Nam, J., Schultz, C. J., Lee, L. Y., Gilson, P. R., Gelvin, S. B., and Bacic, A. 2004. Characterization of the Arabidopsis lysine-rich arabinogalactan-protein AtAGP17 mutant (rat1) that results in a decreased efficiency of Agrobacterium transformation. Plant Physiol. $135: 2162-1271$

Gelvin, S. B. 2003. Agrobacterium-mediated plant transformation: The biology behind the "gene-jockeying" tool. Microbiol. Mol. Biol. Rev. 67:16-37.

Gomez-Gomez, L., Felix, G., and Boller, T. 1999. A single locus determines sensitivity to bacterial flagellin in Arabidopsis thaliana. Plant $\mathrm{J}$. 18:277-284

Goodner, B., Hinkle, G., Gattung, S., Miller, N., Blanchard, M., Qurollo, B., Goldman, B. S., Cao, Y., Askenazi, M., Halling, C., Mullin, L., Houmiel, K., Gordon, J., Vaudin, M., Iartchouk, O., Epp, A., Liu, F., Wollam, C., Allinger, M., Doughty, D., Scott, C., Lappas, C., Markelz, B., Flanagan, C., Crowell, C., Gurson, J., Lomo, C., Sear, C., Strub, G., Cielo, C., and Slater, S. 2001. Genome sequence of the plant pathogen and biotechnology agent Agrobacterium tumefaciens C58. Science 294:2323-2328

Hajdukiewicz, P., Svab, Z., and Maliga, P. 1994. The small, versatile pPZP family of Agrobacterium binary vectors for plant transformation. Plant Mol. Biol. 25:989-994.
Hamilton, R. H., and Fall, M. Z. 1971. The loss of tumor-initiating ability in Agrobacterium tumefaciens by incubation at high temperature. Experientia 27:229-230.

Hammond-Kosack, K. E., and Parker, J. E. 2003. Deciphering plant-pathogen communication: Fresh perspectives for molecular resistance breeding. Curr. Opin. Biotechnol. 14:177-193.

He, P., Shan, L., and Sheen, J. 2007. Elicitation and suppression of microbe-associated molecular pattern-triggered immunity in plant-microbe interactions. Cell Microbiol. 9:1385-1396.

Hellens, R., Mullineaux, P., and Klee, H. 2000. Technical Focus: A guide to Agrobacterium binary Ti vectors. Trends Plant Sci. 5:446-451.

Herlache, T. C., Zhang, H. S., Ried, C. L., Carle, S. A., Zheng, D., Basaran, P., Thaker, M., Burr, A. T., and Burr, T. J. 2001. Mutations that affect Agrobacterium vitis-induced grape necrosis also alter its ability to cause a hypersensitive response on tobacco. Phytopathology 91:966972.

Jones, J. D., and Dangl, J. L. 2006. The plant immune system. Nature 444:323-329.

Katiyar-Agarwal, S., Morgan, R., Dahlbeck, D., Borsani, O., Villegas, A., Jr., Zhu, J. K., Staskawicz, B. J., and Jin, H. 2006. A pathogen-inducible endogenous siRNA in plant immunity. Proc. Natl. Acad. Sci. U.S.A. 103:18002-18007.

Kelman, A., and Sequeira, L. 1972. Resistance in plants to bacteria. Proc. R. Soc. Lond. B 181:247-266.

Kunkel, B. N., and Brooks, D. M. 2002. Cross talk between signaling pathways in pathogen defense. Curr. Opin. Plant Biol. 5:325-331.

Kunze, G., Zipfel, C., Robatzek, S., Niehaus, K., Boller, T., and Felix, G. 2004. The $\mathrm{N}$ terminus of bacterial elongation factor Tu elicits innate immunity in Arabidopsis plants. Plant Cell 16:3496-3507.

Llave, C., Kasschau, K. D., and Carrington, J. C. 2000. Virus-encoded suppressor of posttranscriptional gene silencing targets a maintenance step in the silencing pathway. Proc. Natl. Acad. Sci. U.S.A. 97:1340113406.

Ludwig, A. A., Saitoh, H., Felix, G., Freymark, G., Miersch, O., Wasternack, C., Boller, T., Jones, J. D., and Romeis, T. 2005. Ethylenemediated cross-talk between calcium-dependent protein kinase and MAPK signaling controls stress responses in plants. Proc. Natl. Acad. Sci. U.S.A. 102:10736-10741.

Mallory, A. C., and Vaucheret, H. 2006. Functions of microRNAs and related small RNAs in plants. Nat. Genet. 38 Suppl:S31-36.

Mallory, A. C., Reinhart, B. J., Bartel, D., Vance, V. B., and Bowman, L. H. 2002. A viral suppressor of RNA silencing differentially regulates the accumulation of short interfering RNAs and micro-RNAs in tobacco. Proc. Natl. Acad. Sci. U.S.A. 99:15228-15233.

McCullen, C. A., and Binns, A. N. 2006. Agrobacterium tumefaciens and plant cell interactions and activities required for interkingdom macromolecular transfer. Annu. Rev. Cell Dev. Biol. 22:101-127.

Mlotshwa, S., Schauer, S. E., Smith, T. H., Mallory, A. C., Herr, J. M., Jr., Roth, B., Merchant, D. S., Ray, A., Bowman, L. H., and Vance, V. B 2005. Ectopic DICER-LIKE1 expression in P1/HC-Pro Arabidopsis rescues phenotypic anomalies but not defects in microRNA and silencing pathways. Plant Cell 17:2873-2885.

Navarro, L., Dunoyer, P., Jay, F., Arnold, B., Dharmasiri, N., Estelle, M., Voinnet, O., and Jones, J. D. 2006. A plant miRNA contributes to antibacterial resistance by repressing auxin signaling. Science 312:436-439.

Nurnberger, T., Brunner, F., Kemmerling, B., and Piater, L. 2004. Innate immunity in plants and animals: Striking similarities and obvious differences. Immunol. Rev. 198:249-266.

Pruss, G. J., Lawrence, C. B., Bass, T., Li, Q. Q., Bowman, L. H., and Vance, V. 2004. The potyviral suppressor of RNA silencing confers enhanced resistance to multiple pathogens. Virology 320:107-120.

Robinette, D., and Matthysse, A. G. 1990. Inhibition by Agrobacterium tumefaciens and Pseudomonas savastanoi of development of the hypersensitive response elicited by Pseudomonas syringae pv. phaseolicola. J. Bacteriol. 172:5742-5749.

Rogers, S. G., Klee, H. J., Horsch, R. B., and Fraley, R. T. 1987. Improved vectors for plant transformation: Expression cassette vectors and new selectable markers. Methods Enzymol. 153:253-277.

Santos-Rosa, M., Poutaraud, A., Merdinoglu, D., and Mestre, P. 2008. Development of a transient expression system in grapevine via agro-infiltration. Plant Cell Rep. 27:1053-1063.

Strawn, M. A., Marr, S. K., Inoue, K., Inada, N., Zubieta, C., and Wildermuth, M. C. 2007. Arabidopsis isochorismate synthase functional in pathogen-induced salicylate biosynthesis exhibits properties consistent with a role in diverse stress responses. J. Biol. Chem. 282:59195933.

Truman, W., de Zabala, M. T., and Grant, M. 2006. Type III effectors orchestrate a complex interplay between transcriptional networks to modify basal defence responses during pathogenesis and resistance. Plant J. 46:14-33. 
Uknes, S., Dincher, S., Friedrich, L., Negrotto, D., Williams, S., ThompsonTaylor, H., Potter, S., Ward, E., and Ryals, J. 1993. Regulation of pathogenesis-related protein-1a gene expression in tobacco. Plant Cell 5:159169.

Vance, V. B. 1991. Replication of potato virus X RNA is altered in coinfections with potato virus Y. Virology 182:486-494.

van Loon, L. C., Rep, M., and Pieterse, C. M. 2006. Significance of inducible defense-related proteins in infected plants. Annu. Rev. Phytopathol. 44:135-162.

Veena, Jiang, H., Doerge, R. W., and Gelvin, S. B. 2003. Transfer of TDNA and Vir proteins to plant cells by Agrobacterium tumefaciens induces expression of host genes involved in mediating transformation and suppresses host defense gene expression. Plant J. 35:219-236.

Ward, E. R., Uknes, S. J., Williams, S. C., Dincher, S. S., Wiederhold, D. L., Alexander, D. C., Ahl-Goy, P., Metraux, J. P., and Ryals, J. A. 1991. Coordinate gene activity in response to agents that induce systemic acquired resistance. Plant Cell 3:1085-1094.

Whitham, S., Dinesh-Kumar, S. P., Choi, D., Hehl, R., Corr, C., and Baker, B. 1994. The product of the tobacco mosaic virus resistance gene $N$ : Similarity to toll and the interleukin-1 receptor. Cell 78:1101-1115.

Wood, D. W., Setubal, J. C., Kaul, R., Almeida, N. F., Jr., Woo, L., Chen,
Y., Paulsen, I. T., Eisen, J. A., Karp, P. D., Bovee, D., Sr., Chapman, P., Clendenning, J., Deatherage, G., Gillet, W., Grant, C., Kutyavin, T., Levy, R., Li, M. J., McClelland, E., Palmieri, A., Raymond, C., Rouse, G., Saenphimmachak, C., Wu, Z., Romero, P., Gordon, D., Zhang, S., Yoo, H., Tao, Y., Biddle, P., Jung, M., Krespan, W., Perry, M., GordonKamm, B., Liao, L., Kim, S., Hendrick, C., Zhao, Z. Y., Dolan, M., Chumley, F., Tingey, S. V., Tomb, J. F., Gordon, M. P., Olson, M. V., and Nester, E. W. 2001. The genome of the natural genetic engineer Agrobacterium tumefaciens C58. Science 294:2317-2323.

Yuan, Z. C., Edlind, M. P., Liu, P., Saenkham, P., Banta, L. M., Wise, A A., Ronzone, E., Binns, A. N., Kerr, K., and Nester, E. W. 2007. The plant signal salicylic acid shuts down expression of the vir regulon and activates quormone-quenching genes in Agrobacterium. Proc. Natl. Acad. Sci. U.S.A. 104:11790-11795.

Zipfel, C., Robatzek, S., Navarro, L., Oakeley, E. J., Jones, J. D., Felix, G., and Boller, T. 2004. Bacterial disease resistance in Arabidopsis through flagellin perception. Nature 428:764-767.

Zipfel, C., Kunze, G., Chinchilla, D., Caniard, A., Jones, J. D., Boller, T. and Felix, G. 2006. Perception of the bacterial PAMP EF-Tu by the receptor EFR restricts Agrobacterium-mediated transformation. Cell 125:749-760. 